\title{
PROTEIN BINDING OF SEMISYNTHETIC PENICILLINS
}

\author{
E. L. QuinN \\ Physician in Charge, Division of Infectious Diseases, Department of Medicine, Henry Ford Hospital, \\ Detroit, Michigan.
}

SERUM albumin has been shown by Davis (1943) to interfere with the antibacterial activity of sulfonamides and by Thompsett, Sultz and McDermott (1947) to interfere with the natural penicillins. Furthermore, the degree of interference was different for each of the various agents. The importance of this was shown in both experimental and clinical infections. In the former, a penicillin with a high degree of serum interference appeared to be a less effective therapeutic agent. Clinically, it was noted that commercial lots of penicillin containing large amounts of penicillin $\mathrm{K}$, which is highly bound to serum albumin, were less effective in the treatment of syphilis than amorphous penicillin which contained only a small amount of penicillin K (Committee on Medical Research 1946). In view of these laboratory and clinical findings, both Davis and Thompsett and coworkers stressed that the evaluation of new antimicrobials should include the effect of protein on the agents.

In recent years, a large number of semisynthetic penicillins have been developed as a result of the investigations of research workers at the Beecham Laboratories (Batchelor $\epsilon t$ al., 1959), Institute Superiore de Sanita (Chain, 1962), and other commercial laboratories. In 1961, we became interested in the effect of serum on the semisynthetic penicillins when oxacillin became available for clinical investigation from Bristol Laboratories. This agent was reported to be affected by serum to a degree comparable to penicillin $\mathrm{K}$ (Towson, 1961). Comparative studies were instituted in our laboratory, on the effect of serum on oxacillin, methicillin and the natural penicillins (Quinn and Colville, 1961) and subsequently, this work was extended to include other semisynthetic penicillins and cephalothin (Colville and Quinn, 1961, Quinn et al., 1962). In addition, some of the agents were administered to volunteers and serum concentrations, serum inhibitory activity and urinary excretion were determined. Beside the conventional assay, the inhibitory activity of the same sera was determined in a $50 \%$ serum system. Similar studies of the serum inhibitory activity were also made on patients under treatment with the semisynthetic penicillins. This report constitutes a summation of these observations and includes studies on penicillin $G$, penicillin $V$, phenethicillin, propicillin, methicillin, oxacillin, nafcillin, ampicillin, and cephalothin. We are indebted to various U.S. pharmaceutical companies who made these compounds available.*

Our early studies were carried out with penicillin $G$, oxacillin and methicillin and the results of a sequence of studies with these agents will be presented.

The standard two-fold broth dilution method employing a large inoculum was used to determine the relative susceptibility of clinical isolates. The M.I.C. was taken to be the lowest concentration of antibiotic in the series in which there was no visible growth at 24 hours. In Table $I$, the range and average M.I.C. (minimal inhibitory concentration) of penicillin $G$, oxacillin, and methicillin for 24 strains of nonpenicillinase producing staphylococci is shown. As found by other investigators, penicillin $\mathrm{G}$ was the most potent of these three agents. Oxacillin was, on the average, about four times and methicillin 24 times less potent than penicillin $G$ for these organisms.

Table II similarly depicts the comparative susceptibility of 76 penicillin $G$ resistant staphylococci for the same three antibiotics. As expected, oxacillin averaged about 8 times more potent than methicillin. Penicillin G, of course, was ineffective against these strains. These data, however, do not indicate what effect the presence of serum might have in the test system.

The effect of serum protein on the efficiency of these 3 penicillins was determined by parallel standard two-fold dilution tests

\footnotetext{
*Penicillin G was supplied by E. R. Squibb \& Sons, New Brunswick, N.J.; Penicillin V, phenethicillin and nafcillin by Wyeth Laboratories, Inc., Radour, Pa.; Propicillin and cephalothin by Eli Lilly and Co., Indianapolis, Ind.; Methicillin, oxacillin, and ampicillin by Bristol Laboratories, Syracuse, N.Y.
} 
TABLE I.

The Comparative Antimicrobial Activity* of 24 Strains of Penicillin G Susceptible Staphylococci.

\begin{tabular}{lccc}
\hline M.I.C. & Penicillin G & $\begin{array}{c}\text { No. of Strains } \\
\text { Oxacillin }\end{array}$ & Methicillin \\
$\mu$ g./ml. & 8 & & \\
0.025 or less & 8 & & \\
0.05 & 5 & 10 & \\
0.1 & 2 & 11 & \\
0.2 & 1 & 3 & 14 \\
0.4 & & & 9 \\
0.8 & & & $9.37 \mu \mathrm{g} . / \mathrm{ml}$. \\
1.6 & $0.10 \mu \mathrm{g} . / \mathrm{ml}$. & $0.36 \mu \mathrm{ml}$. & 2.37 \\
3.2 & Mean &
\end{tabular}

* Standard two-fold tube dilution method. Trypticase soy broth diluent. Average inoculum: $8.52 \times 10^{6}$.

TABLE II.

The Comparative Antimicrobial Activity* of 76 Strains of Penicillin G Resistant** Staphylococci.

\begin{tabular}{|c|c|c|c|}
\hline $\begin{array}{l}\text { M.I.C. } \\
\mu \mathrm{g} . / \mathrm{ml} .\end{array}$ & Penicillin G & $\begin{array}{c}\text { No. of Strain } \\
\text { Oxacillin }\end{array}$ & Methicillin \\
\hline $\begin{array}{l}0.2 \\
0.4 \\
0.8 \\
1.6 \\
3.1 \\
6.2\end{array}$ & & $\begin{array}{l}15 \\
47 \\
14\end{array}$ & $\begin{array}{l}14 \\
46 \\
16\end{array}$ \\
\hline
\end{tabular}

12.5 to $800 \quad 76$

Mean $\quad 0.42 \mu \mathrm{g} . / \mathrm{ml} . \quad 3.45 \mu \mathrm{g} . / \mathrm{ml}$.

* Standard two-fold tube dilution method. Trypticase soy broth diluent.

Average inoculum: $8.06 \times 10^{6}$.

**All strains produced penicillinase.

TABLE III.

Effect of Protein on Efficiency of Three Penicillins.

Final Concentration of diluent

T-Soy broth

$1.75 \%$ bovine albumin

$7 \%$ bovine albumin

$50 \%$ human serum

Undil. human serum***
Aver. M.I.C.* and Percentage Efficiency**

Penicillin G. Oxacillin Methicillin

$.021(100 \%) \quad .156(100 \%) \quad .936(100 \%)$

$.028(75 \%) \quad .244 \quad(64 \%) \quad .975 \quad(96 \%)$

$.055 \quad(38 \%) \quad 858 \quad(18 \%) \quad 1.87 \quad(50 \%)$

$\begin{array}{llllll}.049 & (49 \%) & 1.040 & (13 \%) & 1.56 & (83 \%)\end{array}$

$\begin{array}{llllll}.079 & (27 \%) & 2.03 & (8 \%) & 1.09 & (86 \%)\end{array}$

\footnotetext{
*In $\mu \mathrm{g} . / \mathrm{ml}$., aver. of 3-9 determinations. Test organisms: Staph. aureus, White strain. Inoculum: $9 \times 10^{5}$.

$* *$ Percentage Efficiency $=\frac{\text { M.I.C. in protein media }}{\text { M.I.C. in T-soy broth }} \times 100$

***Electrophoretic analysis: Total Protein $7.9 \mathrm{~g} . / 100 \mathrm{ml}$.,

Albumin 5.02 g. $/ 100 \mathrm{ml}$.
}

utilizing the following diluents: trypticase soy broth, $1.75 \%$ and $7 \%$ bovine albumin and $50 \%$ and undiluted pooled human serum (Table III). The M.I.C. of the
3 penicillins in the various media represents an average of 3 to 9 determinations It can be seen that as the concentration of bovine albumin or human serum increased 
TABLE IV.

The Average Comparative Antimicrobial Activity of 100 Strains of Staphylococci.

Average M.I.C.

\begin{tabular}{lccc} 
& \multicolumn{3}{c}{ Average M.I.C. } \\
& Penicillin G & Oxacillin & Methicillin \\
Penicillin G Susceptible Staph. & 0.10 & 0.36 & 2.37 \\
In broth & 0.37 & 4.5 & 2.75 \\
In whole serum* & - & 0.42 & 3.45 \\
Penicillin G Resistant Staph. & - & 5.25 & 4.0 \\
$\quad$ In broth & - & \\
In whole serum* &
\end{tabular}

*Calculated from percentage efficiency.

TABLE V.

The Comparative Loss of Antimicrobial Activity and Protein Binding of 8 Penicillins and Cephalothin.

\begin{tabular}{lcc}
\hline & $\begin{array}{c}\text { Per cent loss of antibiotic } \\
\text { activity in serum* }\end{array}$ & $\begin{array}{c}\text { Bound as per cent of total } \\
\text { antibiotic in serum** }\end{array}$ \\
Penicillin G & 73 & 68 \\
Penicillin V & 76 & 75 \\
Phenethicillin & 75 & 71 \\
Propicillin & 94 & 88 \\
Methicillin & 14 & 35 \\
Oxacillin & 92 & 88 \\
Nafcillin & 86 & 84 \\
Ampicillin & 25 & 21 \\
Cephalothin & 79 & 70 \\
\hline
\end{tabular}

*Inverse of percentage efficiency in broth compared to undiluted serum.

**Determined by dialysis of undiluted serum at $4^{\circ} \mathrm{C}$. Antibiotic concentration $10 \mu \mathrm{g}$./ml. $\mathrm{pH} 7.4$.

the M.I.C. of each penicillin also increased. The only exception was methicillin in the $50 \%$ and undiluted human serum. Using the antibacterial activity of penicillin in broth as the reference point, it is possible to calculate the efficiency of each agent in the various test conditions according to the formula shown. These results are enclosed in parentheses in the table. It can be seen that as the concentration of bovine albumin was increased, there was a decrease in the efficiency of each of the penicillins. Methicillin was least affected by bovine albumin, penicillin $G$ was intermediate and oxacillin exhibited a marked decrease in activity in this test system.

In pooled human serum, methicillin was the most active agent. The interference of $50 \%$ and whole serum was similar, indicating that $50 \%$ or possibly a lesser concentration of human serum may result in maximum interference of activity by th:s agent. In contrast, the interference by human serum with the activity of oxacillin was marked and was slightly greater in whole than in $50 \%$ serum. Interference with penicillin $\mathrm{G}$ was again intermediate and greatest in whole serum.

In Table IV the average M.I.C. of the 3 penicillins for the 100 strains of staphylococci referred to above is compared when determined in broth and in whole serum. The validity of the calculated values for whole serum was confirmed by actual test of the M.I.C. of a number of the organisms in this medium. It is evident that oxacillin was 7 to 8 times more active than methicillin in broth; in whole serum, however, methicillin was the more potent agent. It should also be noted that the potency of penicillin $G$ for the sensitive strains of staphylococci was much greater than oxacillin and methicillin in the protein diluent. This will be commented on later in the pharmacologic studies to be described.

The possibility that the serum might be inhibitory in the absence of antibiotics, a well known effect of serum on the growth of certain bacteria (Elias, Morrion and Speicher, 1945), was evaluated by performing growth curves of the test organisms in the various diluents. Results with the four test organisms utilized in our studies are depicted in Figure 1. It can be seen that the various diluents neither inhibited or enhanced the growth in trypticase soy broth. The pooled sera, however, was found to inhibit the growth of the test strain 
of penicillin $\mathrm{G}$ resistant staphylococcus and the alpha haemolyte streptococcus. This was not a constant effect, however, as other lots of pooled serum failed to inhibit any of the test organisms. Accordingly, preliminary serum testing of this type was always carried out to indicate which lots of pooled serum were suitable diluents for performing these studies.

The percentage loss of antibiotic activity of 8 penicillins and cephalothin in $100 \%$ serum is listed in Table $\mathrm{V}$. These data are compared with the results of dialysis experi $\rightarrow$ ments. The bound drug is expressed as the percentage of the total antibiotic in the serum In the dialysis tests, as previously described (Quinn et al., 1962), each agent was addeck in a concentration of $10 \mu \mathrm{g} . / \mathrm{ml}$. to normal pooled human serum buffered at $\mathrm{pH} 7.4{ }^{\circ}$ Dialysis was carried out at $4^{\circ} \mathrm{C}$. for $48^{\circ}$ hours using a magnetic stirrer. Equilibriund was reached in all cases in 24 to 48 hours: It is apparent that methicillin and ampicillin 
SERUM CONCENTRATION

PENICILLIN

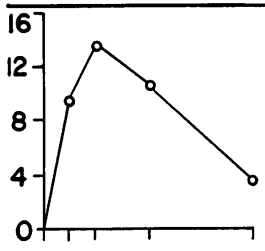

METHICILLIN

(I.5 G. I.M. Dose)

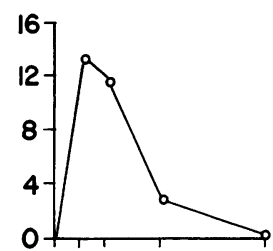

PEN $\mathrm{P}-12$

(1.5 G. Oral Dose)

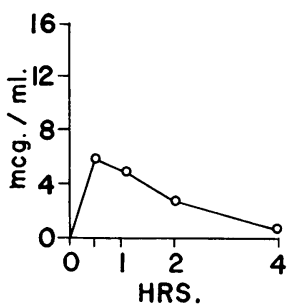

K- PEN V

(I.25 G. Oral Dose)

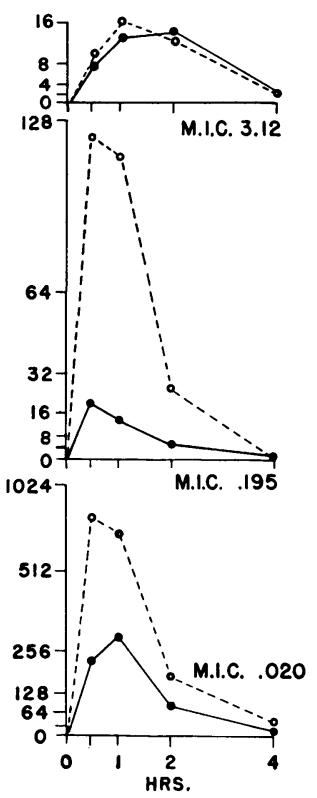

-- - - T T-S BROTH

FIG. 2.-The average serum concentration and serum inhibitory activity after a single fasting dose of methicillin, oxacillin, and penicillin $\mathbf{V}$ in a cross-over study in ten normal adults. Concentration assayed by the Sarcina lutea cup-plate method utilizing $1.75 \%$ bovine albumin as the reference standard and serum diluent. Serum activity, expressed as the reciprocal of the maximal inhibition dilution, for a nonpenicillinase-producing Staphylococcus aureus (ID White) at an average inoculum of $2 \times 10^{6}$. Serum diluted in Trypticase soy broth (T-S Broth) and 50\% pooled human serum. (Reproduced by permission of Antimicrobial Agents and Chemotherapy, 1961, p. 604).

lost the least amount of activity and were the least bound. Penicillin G, penicillin V, phenethicillin and cephalothin occupied an intermediate position. Propicillin, oxacillin and nafcillin were markedly affected by the presence of whole serum and were highly bound to serum proteins. The direct proportion of the loss of activity caused by serum to the degree of binding to protein for each agent has been cited as indirect evidence that the portion of the drug that is bound is inactive against bacteria (Davis, 1943; Thomsett, 1947).

The serum binding data are in general agreement with those reported by other investigators. Variations in the results in published reports are probably related to difference in the methods used particularly in relation to antibiotic and serum concentration, $\mathrm{pH}$, temperature, etc., which alters the dissociation of penicillin from serum proteins.

The binding of drugs and other substances to serum proteins may also be determined by ultrafiltration methods. Kirby and his colleagues (Kirby, Rosenfeld and Brodie, 1962; Sidell et al., 1963) have reported that tube dilution and ultrafiltration give comparable serum binding values for methicillin, oxacillin, nafcillin and cephalothin (17 and 28,87 and 86 , 56 and 69, and 66 and 56\% respectively for each method and each antibiotic).

In our laboratory, the ultrafiltration method 


\section{PENICILLIN}

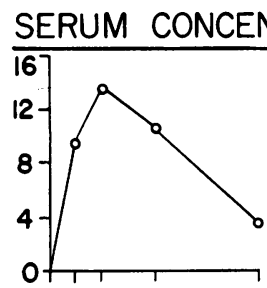

METHICILLIN

(I.5 G. I.M. Dose)
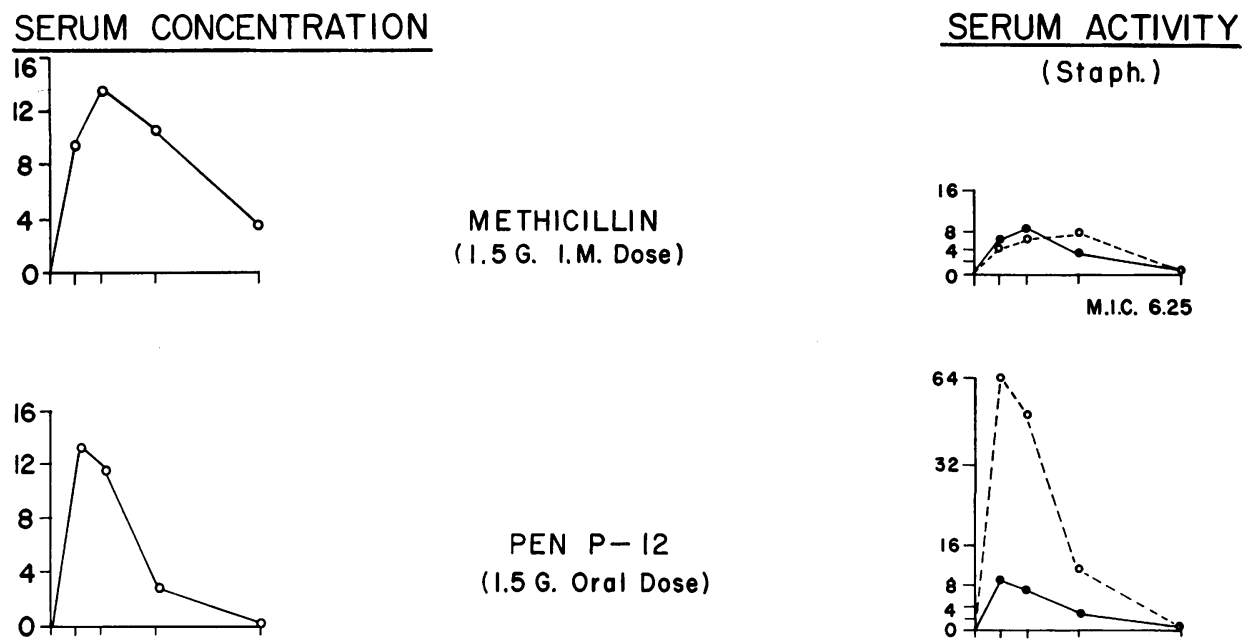

PEN $P-12$

(I.5 G. Oral Dose)
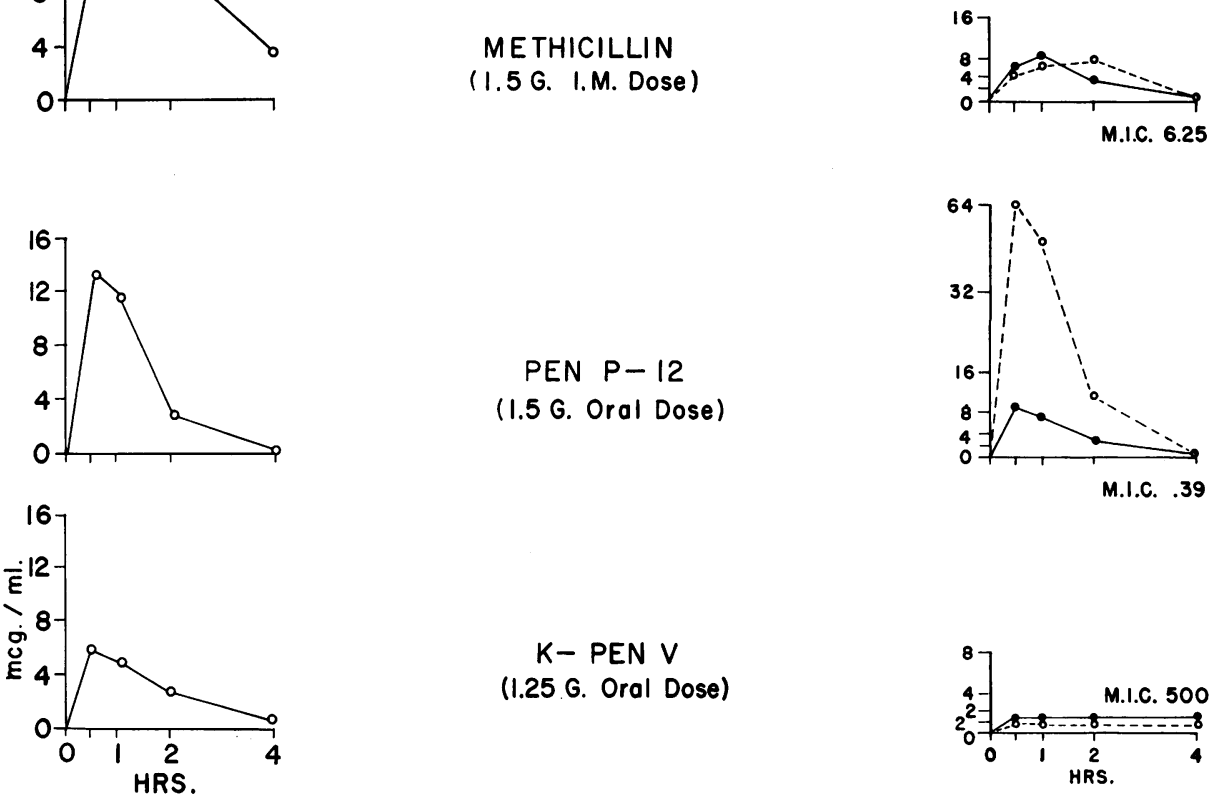

K- PEN V

(I.25 G. Oral Dose)

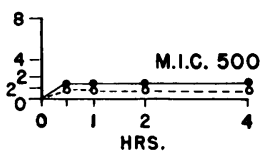

$0---0$ T-S BROTH

FIg. 3.-Activity of the sera illustrated in Fig. 2 for a penicillinase-producing Staphylococcus aureus (ID 76) at an average inoculum of $1 \times 10^{6}$.

of Prasad and Flink has been used. For example, we have shown (Jones and Quinnunpublished) that 91 to $94 \%$ of oxacillin was bound to serum in ultrafiltration tests. This compares to $92 \%$ by tube dilution in whole serum, and to $88 \%$ by dialysis (Table V).

The results of the cross-over study employing a large single dose of penicillin $\mathrm{V}$, methicillin and oxacillin is shown, Figures 2 and 3 . The average serum concentration, dose and route of administration, and average serum activity in broth and $50 \%$ serum are indicated. In Figure 2 the serum activity utilizing a nonpenicillinase producing staphylococcus as the test organism is presented. It is apparent that the average serum concentrations of methicillin and oxacillin (labelled Pen P-12 in these figures) were comparable at $\frac{1}{2}$ and 1 hour, but intramuscularly administered methicillin produced more prolonged levels. Penicillin V peak serum concentrations were 2 to 3 times less than methicillin and oxacillin, although the dose of potassium penicillin $\mathrm{V}$ was only slight less, i.e., $1.25 \mathrm{~g}$. vs. $1.5 \mathrm{~g}$. for methicilli and oxacillin.

It can be seen that the inhibitory activity in $50 \%$ serum system was less for each. penicillin than when broth was employed as the diluent. The discrepancy is greatest for oxaciplin, intermediate for penicillin $\mathrm{V}$ and least foi methicillin. Comparison of serum concentratiof and serum antibacterial activity indicated. that approximately $83 \%$ of methicillin $11 \%$ of oxacillin, and $17 \%$ of penicillin remained biologically active in the presenges of $50 \%$ serum. These data correlate closely with the efficiency and serum binding \& methicillin, oxacillin and penicillin $V$ \& shown above.

It can be seen that methicillin and oxacillin produced equivalent peak serum concentrations 


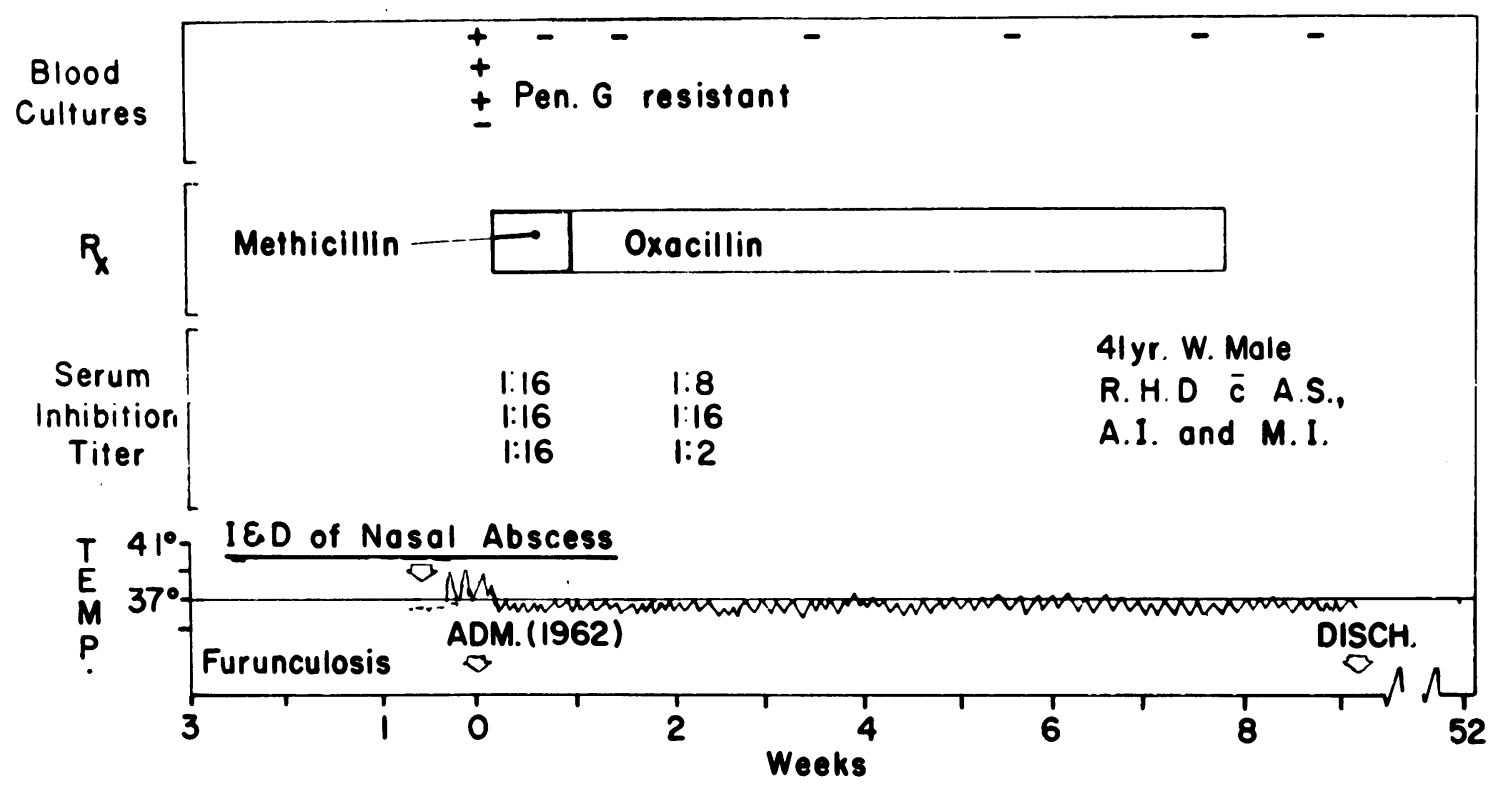

FIG. 4.-Clinical and laboratory findings in a case of acute endocarditis due to Staph. aureus. The serum inhibition titers of methicillin and oxacillin at 1,2 and 4 hours after one of multiple doses. Initially, 2 grams of methicillin were given intramuscularly and later 2 grams of oxacillin were given orally every 4 hours. The inhibition titer was determined in $50 \%$ human serum employing the causative organism with a M.I.C. of methicillin of $3.12 \mu \mathrm{g} . / \mathrm{ml}$. and of oxacillin of $0.4 \mu \mathrm{g} . / \mathrm{ml}$. in a broth diluent.

Since the test organism was approximately 15 times more sensitive to oxacillin than methicillin, one might expect oxacillin to produce considerably greater serum activity than methicillin, and this was true when broth was used as the diluent. However, it is apparent that in the $50 \%$ serum system, oxacillin and methicillin induced equivalent serum antimicrobial activity. These findings are best explained by the marked serum interference of oxacillin.

It can also be noted that despite lower serum concentration and greater serum interference of penicillin $\mathrm{V}$ compared to methicillin, the peak serum activity in a $50 \%$ serum protein system was 1:256 for penicillin V compared with 1:16 for methicillin. This result most obviously reflects the much greater potency (56 times) of penicillin $\mathrm{V}$ for this organism.

Figure 3 shows the serum activity when the same sera were examined using penicillinase producing staphylococcus as the test organism. This organism was resistant to $500 \mu \mathrm{g} . / \mathrm{ml}$. of penicillin $\mathrm{V}$ and no serum activity was detected either in the broth or $50 \%$ serum diluent. Methicillin containing sera displayed little evidence of serum interference while oxacillin activity was considerably less in $50 \%$ serum than in broth. It is again apparent that the greater activity of oxacillin is compromised by its susceptibility to serum interference with a resultant equivalent inhibitory activity of both methicillin and oxacillin in the serum diluent test system.

Urinary excretion was also studied in this cross-over test. $49.5 \%$ methicillin, $19.6 \%$ of oxacillin and $31 \%$ of the administered dose of penicillin $\mathrm{V}$ were recovered in 12 hours in the urine as determined by bioassay.

The course of a successfully treated patient with acute endocarditis due to a penicillin $G$ resistant staphylococcus is diagramed in Figure 4. He receives 2 grams of methicillin administered intramuscularly every 4 hours for 6 days, then oxacillin given orally in the same dose. The titers of serum inhibition for the causative organism were in the usual 
range and as noted in Figure 3, are slightly lower and less sustained for oxacillin. These titers were determined in $50 \%$ serum 1,2 and 4 hours after the preceding dose. Based on this type of data, we have employed equivalent doses of methicillin and oxacillin in the treatment of serious staphylococcal infections.

It is apparent that many factors, for example, potency, absorption, serum binding, tissue concentration, serum and tissue inactivation and excretion may all, or in part, influence the resultant antimicrobial effect of an antibiotic agent in vivo.

The present investigation serves to illustrate the interplay of certain of these factors and indicates that the various penicillins studied differed with respect to potency, serum interference and binding and urinary excretion of active material. There would seem to be little reason to doubt that the penicillins also differ with respect to absorption, tissue distribution, and serum and tissue inactivation. With regard to these latter factors, the pharmacodynamics of two highly bound penicillins, namely, penicillin $\mathrm{K}$ and oxacillin, has been reported to be similar in several important respects. It has been shown that penicillin $K$ as compared to penicillin $\mathrm{G}$ was concentrated in the tissues, especially the liver, to a much greater degree, was excreted in larger amounts in the bile, disappeared from the serum more rapidly and was recovered to a lesser extent in the urine (Eagle, 1947; Eagle and Newman, 1947; Price, Randall and Welch, 1947; Richardson et al., 1946; Coghill, Osterberg and Hazel, 1946; Hobby, Burkhart and Hyman, 1946). Pindell, Bierwagen and Tisch (1961) have shown that oxacillin has a similar metabolic fate.

In our studies, oral oxacillin disappeared from the serum more rapidly and was excreted in lesser amounts in the urine than methicillin. These data, together with the presumed reversibility of serum binding of these agents and the inverse relationship of protein binding to con- centration, suggest that this type of a highl⿳⺈⿴囗十 bound chemotherapeutic agent should be administered in somewhat larger and possibly. more frequent doses than lesser bound agents:

\section{REFERENCES}

Batchelor, F. R., Doyle, F. B., Nayler, J. H. C and Rolinson, G. N. (1959), Nature (Lond. 183, 257.

Chain, E. P. (1962), Ciba Foundation. Resistance of Bacteria to the Penicillins. Edited by A. V. S. DeReuck and M. P. Cameron. p. 3, Boston Little Brown, (Study Group No. 13).

COGHILl, R. D., OSTERBERG, A. E., and HAZEL, G. R. (1946), Science, 103, 709.

Colville, J. M., and QuinN, E. L. (1962), Antimicr bial Agents and Chemotherapy, 1961, p. 600.

Committee ON MEdical Research, THE UNITE States Health Service and The FoOd anio Drug Administration (1946), J. Amer. meds Ass., 131, 271.

Davis, B. D. (1943), J. clin. Invest., 22, 753.

EAGLe, H. (1947), J. exp. Med., 85, 163.

EAGLE, H., and NEWMAN, E. V.'(1947), J. clin. Invest. 26, 903.

Elias, W. F., Morrion, H. J., and Speicher, T. (1945), Science, 102, 223.

HobBy, G. L., BURKHART, B., and HymaN, B. (1946)D Proc. Soc. exp. Biol. (N.Y.), 63, 296.

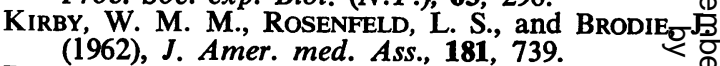

Pindell, M. H., BIerwagen, M. E., and Tisch, D\&E. (1961). At Conference on 5-methyl-3-Phen 1 - 4 Isoxazolyl Penicillins, sponsored by Bristol Labo oratories, New York, 1961.

Prasad, A. S., and Flink, E. B. (1957), J. $a \stackrel{a p p}{p}$ Physiol., 10, 103.

Price, C. W., Randall, W. A., and Welch, H. (1947) J. Amer. pharm. Ass. sci. Ed., 36, 19.

QuinN, E. L., and Colville, J. M. (1961).At Con@ ference on 5-methyl-3-Phenyl-4-Isoxazalyl Pen\$ icillin, sponsored by Bristol Laboratories, New York, 1961.

QuinN, E. L., Colville, J. M., Ballard, L., JoNeS? D., and DeBNAM, F. (1963), Antimicrobial Agents and Chemotherapy, 1962, p. 339.

Richardson, A. P., Miller, I., Schumackor, C. JAMBOR, W., PANSY, F., and LAPEDES, D. (1946) Proc. Soc. exp. Biol. (N.Y.), 63, 514.

Sidell, S., BurdicK, R. E., BRoDIE, J., Bulger, R. Jं and KIRBY, W. M. M. (1963), Arch. intern. med $112,21$.

ThOMPSETT, R., SULTZ, S., and MCDERMotT, W⿳ (1947), J. Bact., 53, 581.

Towson, R. T. (1961), Research Division, Bristof Laboratories. 